\title{
Primary Hemireplacement Arthroplasty in the Management of Unstable Intertrochanteric Fractures
}

\author{
Rapaka Radhakrishna ${ }^{1}$, Ananthula Krishna Reddy²
}

\author{
${ }^{1}$ Associate Professor, Department of Orthopaedics, Osmania Medical College and General Hospital, Hyderabad, \\ Telangana, India. ${ }^{2}$ Associate Professor, Department of Orthopaedics, Osmania Medical College and General Hospital, \\ Hyderabad, Telangana, India.
}

\section{ABSTRACT}

\section{BACKGROUND}

Intertrochanteric fractures ${ }^{1}$ are a major cause of morbidity and mortality in the elderly population. They make up to $55 \%$ of all hip fractures. $35-40 \%$ of these fractures are unstable three- and four-part configurations with displacement of posteromedial cortex. Comminuted and unstable ${ }^{2}$ inter-trochanteric fractures in the elderly osteoporotic patients pose challenging problems with increased rate of morbidity and mortality. Conservative treatment with traction and prolonged immobilization result in several dreaded complications. Surgery in these fractures is very important for the prevention of complications associated with conservative treatment like pressure sores, pulmonary infection, atelectasis, malunion etc. Osteosynthesis ${ }^{3}$ by internal fixation does provide immediate fracture fixation, but in elderly patients with osteoporotic bones, complications like implant loosening, implant penetration, loss of fixation, cut through of implant are not uncommon. As a result, unstable intertrochanteric fractures in elderly patients are associated with high rates of morbidity and mortality 4

\section{METHODS}

In our study during the period from April 2017 to April 2019, 30 patients with comminuted intertrochanteric fracture femur were operated by using the cemented bipolar prosthesis at Osmania General Hospital who were more than 70 years of age with osteoporotic bone.

\section{RESULTS}

Functional evaluation was done by Harris hip score. Excellent to fair results were obtained in $28(93 \%)$ cases, and in $2(7 \%)$ cases the results were poor. Mean hospital stay was $12+/-0.6$ days. There was one case of a superficial operative site infection and one case of a deep infection. There was one case with implant loosening 5 , and sinking noted in one case. Limb length discrepancy was noted in 3 cases. Osteoporotic bones with comminuted fractures do not provide a good purchase for the implants, which subsequently leads to an early implant failure resulting in collapse of the fracture. Early mobilization is very essential particularly in patients with other medical co-morbidities. Both, stability and early ambulation are only possible with primary cemented hemiarthroplasty. It thus helps in preventing postoperative complications of prolonged recumbency such as pressure sores, pneumonia, atelectasis, etc. The concept of dual bearing surfaces offers considerable advantages, it results in sharing of motion at two surfaces and thus reducing erosion 6 at the acetabular joint surface.

\section{CONCLUSIONS}

Primary hemi replacement bipolar arthroplasty offers early painless mobility, ease of rehabilitation and early return to function, especially in complex trochanteric fractures, in the elderly and osteoporotic group. Our results are comparable to previous studies described in literature.

\section{KEY WORDS}

Intertrochanteric Fracture, Hemiarthroplasty, Bipolar Prosthesis
Corresponding Author: Dr. Ananthula Krishna Reddy, C/o. Bhuvana Hospital, D. No. 9-55/74, Keshava Nagar, Boduppal, Hyderabad-500092, Telangana, India.

E-mail: akreddyortho@gmail.com

DOI: $10.14260 /$ jemds/2019/627

Financial or Other Competing Interests: None.

How to Cite This Article: Radhakrishna $R$, Reddy AK. Primary hemireplacement arthroplasty in the management of unstable intertrochanteric fractures. J. Evolution Med. Dent. Sci. 2019;8(38):2886-2890, DOI: 10.14260/jemds/2019/627

Submission 04-07-2019, Peer Review 10-09-2019, Acceptance 16-09-2019, Published 23-09-2019.

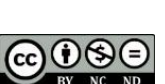




\section{BACKGROUND}

Intertrochanteric fractures are a major cause of morbidity and mortality in the elderly population. The incidence of all hip fractures is approximately 80 per 100,000 persons. Intertrochanteric fractures make up to $55 \%$ of all hip fractures. $35-40 \%$ of these fractures are unstable three- and four-part configurations with displacement of posteromedial cortex. Surgery in these fractures is very important in the elderly patients for the prevention of complications associated with conservative treatment like pressure sores, pulmonary infection, atelectasis, malunion etc. Osteosynthesis by internal fixation does provide immediate fracture fixation, but in elderly patients with osteoporotic bones, complications like implant loosening, implant penetration 7 , loss of fixation, cut through of implant are not uncommon. The failure rates of these unstable fractures fixed with sliding hip screws averages approximately 6-32\%. PFN failure $^{8}$ rates are $5-15 \%$. As a resultunstable intertrochanteric fractures in elderly patients are associated with high rates of morbidity and mortality. ${ }^{9}$ Thus, is the emerging role of cemented bipolar hemiarthroplasty in the management of unstable intertrochanteric fractures, aimed at early rehabilitation and mobilization.

The aim of this study is to evaluate the functional and clinical outcomes of cemented bipolar hemiarthroplasty as a primary treatment of choice for unstable intertrochanteric fractures in the elderly age group.

\section{METHODS}

During the period from April 2017 to April 2019, 30 patients with unstable intertrochanteric fracture femur were treated by using the cemented bipolar prosthesis at Osmania general Hospital. This study was approved by the institutional ethics committee. All the patients provided written informed consents.

\section{Inclusion Criteria}

1. Patients more than 70 years of age with fresh and old intertrochanteric fracture femur.

2. With osteoporotic bone.

\section{Exclusion Criteria}

1. Intertrochanteric fracture femur in patients below 70 years.

2. Intertrochanteric Fracture femur associated with fracture shaft of femur, and acetabular fracture.

3. In the presence of any sepsis or any localized septic focus in the body.

Preoperative templating of radiographs was done to determine the approximate size and position of the stem and the approximate femoral neck offset. All surgical procedures were performed by using Moore's approach, with the patients in the lateral position. Skin incision was taken from a point 10 $\mathrm{cm}$ distal to posterior superior iliac spine and extended distally and laterally parallel to the fibres of gluteus maximus to the posterior margin of the greater trochanter and then directed about $10 \mathrm{cms}$ parallel to the femoral shaft. After incising the deep fascia gluteus maximus was split in the direction of its fibres by blunt dissection. By retracting the proximal fibres of the muscle proximally, the greater trochanter is exposed. Distal fibres are retracted distally and partly divided at their insertion into the linea-aspera in line with the distal part of the incision. The fractured greater trochanter is reflected anteriorly. The external rotators and the piriformis tendons were divided at their insertions after tagging them for easier identification and reattachment. After incising the capsule and exposing the neck of the femur, osteotomy $^{10}$ was done on the neck, and the hip was dislocated posteriorly. The head of the femur was levered out of the acetabulum and the size was measured using template, the size was confirmed using a trial prosthesis ${ }^{11}$. The femoral shaft was rasped using a broach (rasp) and prepared for the insertion of the prosthesis. Bipolar stem was cemented in place in $10-15^{\circ}$ of anteversion using standard cementing techniques - lavage, cleaning, drying and plugging of the canal. Then the greater trochanter was put back in place, in case of comminution it was fixed using a SS wire or TBW 12 . After suturing the capsule, the external rotators were sutured back, the wound was closed in layers over a suction drain, which is removed at the first change of dressing after 48 hours.

\section{Postoperative Care}

Mobilization- From the first postoperative day, the patient was allowed to weight bear depending on his/her pain tolerance and encouraged to walk thereafter. Sitting crosslegged and squatting were not allowed. Suture removal was done on the 10 th to the 12 th postoperative days and the patients were discharged later.

\section{Protocol for Follow Up}

All patients were followed up at 6 weeks, 3 months and 6 months post-operatively with the longest interval being one year. Clinical evaluation was done by using Harris Hip score ${ }^{13}$. The HHS score gives a maximum of 100 points. Pain receives 44 points, function 47 points, range of motion 5 points, and deformity 4 points. Function is subdivided into activities of daily living (14 points) and gait (33 points). The higher the HHS, the less dysfunction ${ }^{14}$.

Statistical analysis of HHS is given below.

\section{RESULTS}

In the present study, thirty (30) cases of Intertrochanteric fracture femur were treated with cemented bipolar hemiarthroplasty between April 2017 to April 2019. Of them 18 were female and 12 male. 15 were in the age group of 70 75. Remaining 15 were $>75$ years age. In our study commonest mode of intertrochanteric injury was due to trivial fall, while walking at house. This is probably due to severe osteoporosis in elderly age group. 2 patients had type I fractures, 13 patients had type II fractures, 9 had type III fractures, and 6 had a type IV fracture (Boyd and Griffin's Classification). Singh's index (grades of osteoporosis) was grade III in 19 patients and it was grade II in 11 patients. The mean operative time was $90 \pm 11$ minutes. The average 
duration of hospital stay was 14 days, with a range of 10-25 days. The follow up period ranged from fourteen months to twenty-four months with an average follow up of eighteen months. Functional evaluation was done by Harris Hip Score.

\begin{tabular}{|c|c|c|c|}
\hline \multicolumn{2}{|c|}{ Range of Movement } & No. of Patients & Percentage \\
\hline Excellent & $90-100$ & 6 & $20 \%$ \\
\hline Good & $80-89$ & 18 & $60 \%$ \\
\hline Fair & $70-79$ & 4 & $13.3 \%$ \\
\hline Poor & $<70$ & 2 & $6.7 \%$ \\
\hline \multicolumn{3}{|c|}{ Tarris Hip Score (At the End of One Year) } \\
\hline \multicolumn{2}{|c|}{$\begin{array}{l}\text { Total } \\
\text { were poor. }\end{array}$}
\end{tabular}

Superficial infection noticed in 2 cases and in one case deep infection was noted. Limb length discrepancy ${ }^{15}$ was noted in 3 cases $[>1 \mathrm{~cm}]$. There was no incidence of postoperative dislocations of the prosthesis. Implant loosening was noted in one case, and sinking noted in one case. Most of the patients had a pain free mobile hip with a full range of flexion, abduction, adduction and adequate range of rotations.
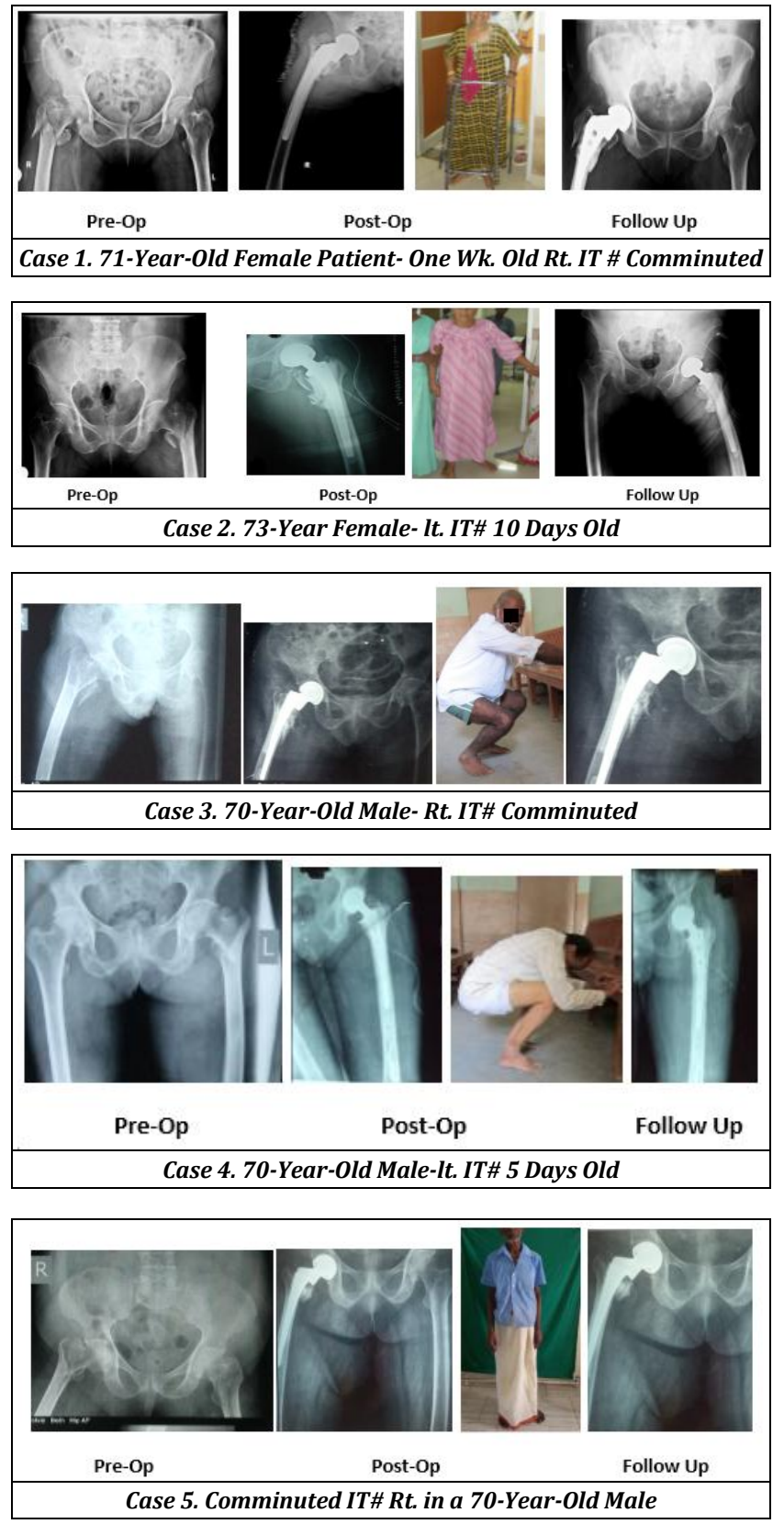
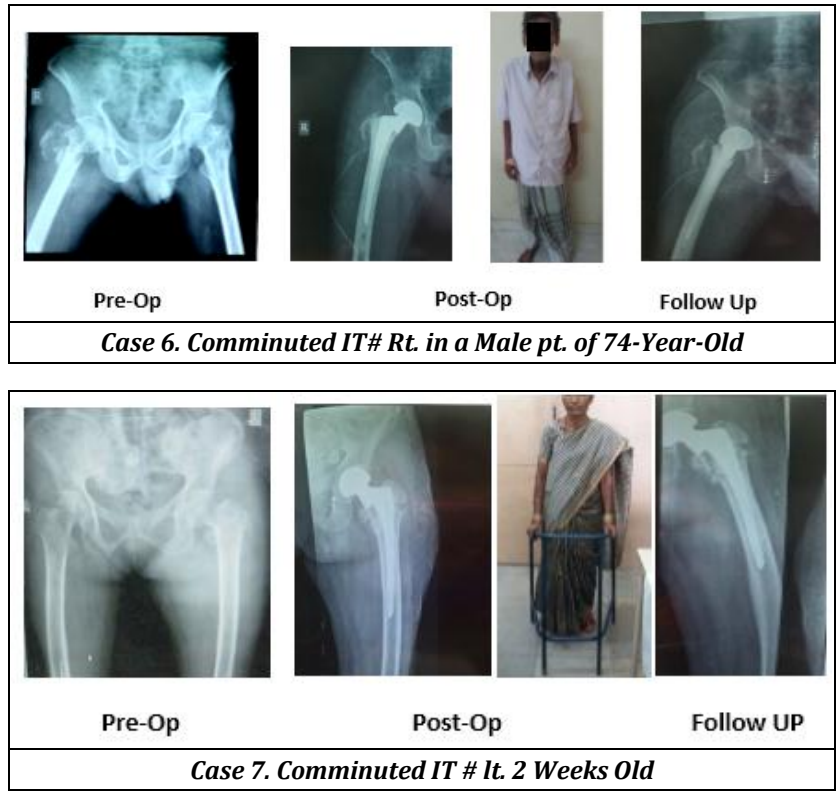

\begin{tabular}{|c|c|c|c|c|c|c|}
\hline Results & Score & Sherwani & Mosheir & Lestrange & Gilberty & Present Study \\
\hline Excellent & $91-100$ & $31 \%$ & $40 \%$ & $39.6 \%$ & $64 \%$ & $06(20 \%)$ \\
\hline Good & $80-89$ & $46 \%$ & $25 \%$ & $31.2 \%$ & $28 \%$ & $18(60 \%)$ \\
\hline Fair & $70-79$ & $15 \%$ & $23 \%$ & $15.3 \%$ & - & $04(13.3 \%)$ \\
\hline Poor & $<70$ & $08 \%$ & $12 \%$ & $13.9 \%$ & $0.8 \%$ & $02(6.7 \%)$ \\
\hline \multicolumn{7}{|c|}{ Analysis of Results } \\
\hline
\end{tabular}

\section{DISCUSSION}

Comminuted and unstable inter-trochanteric fractures in the elderly osteoporotic patients poses challenging problems with increased rate of morbidity and mortality. Till the third decade of the twentieth century trochanteric fractures were treated conservatively. Conservative treatment regimens included, simple support with pillows or splinting to the opposite limb, Buck's (Skin) traction, well-leg traction, plaster spica immobilization, Russell's balanced traction and skeletal traction through the lower femur or upper tibia. In 1931, Smith-Peterson ${ }^{7}$ reported their series of open nailing with the triflanged nail. In 1937, Lawson developed a plate to be attached to the Smith Peterson nail. In 1950, Earnest Roll in Germany was the first to use a sliding device for internal fixation of trochanteric fractures. In 1964, The Richards Manufacturing Company and Mr. Ian McKenzie of the Royal National Orthopaedic Hospital developed the Sliding Compression Screw ${ }^{16}$. Clawson made several modifications, and in its current form the device is known as the Richards Compression Screw. Dissatisfaction with use of a sliding hip screw in unstable fracture patterns led to the development of intramedullary devices.

In a stable, and well-reduced inter trochanteric fractures that were treated by osteosynthesis with dynamic hip screw fixation or proximal femoral nailing, the union rates are as high as $90 \%$ to $100 \%$. But only $50 \%$ union rates have been noted in unstable fractures, with postero medial comminution, and severe osteoporosis. Internal fixation of these unstable fractures though reduces the pain, does not permit early mobilization with the fear of failure of fixation and thus the morbidity remains same. Early mobilisation of the patient following surgeries are very important in the elderly age group for preventing severe cardiorespiratory complications and bed sores. 
Osteoporotic bones with comminuted fractures do not provide a good purchase for the implants, which subsequently leads to an early implant failure --implant loosening, implant penetration, loss of fixation, cut through of implant resulting in collapse of the fracture, with migration of the femoral head into the varus ${ }^{17}$ and retroverted ${ }^{17}$ position, resulting in shortening and decreased abductor lever arm, as a result instability and limp. Hemiarthroplasty is the best alternative. Both, stability and early ambulation are only possible with cemented hemiarthroplasty. Early mobilization is very essential particularly in patients with other medical co-morbidities. Many of the complications associated with internal fixations can be avoided by performing hemiarthroplasties.Primary hemiarthroplasty helps in preventing postoperative complications of prolonged recumbency such as pressure sores, pneumonia, atelectasis, etc. Bipolar hemiarthroplasty was introduced to address the complications of unipolar implants like acetabular wear, protrusion, loosening and dislocation. The concept of dual bearing surfaces in prosthesis, offers considerable advantages. It results in sharing of the motion at the two surfaces and hence, it reduces the net wear at either surface, thus reducing erosion at the acetabular joint interface ${ }^{18}$. In addition, the total range of motions at the joint is increased. Stems were designed, more in lines with total hip replacement designs, to lessen component loosening. Cemented fixation is advantageous for achieving the initial implant stability and a rapid rehabilitation. In our study of bipolar hemiarthroplasty of the hip, we have evaluated 30 cases that were performed using Bipolar Prosthesis at our Hospital. The study was conducted over a period of 2 years i.e. April 2017 to April 2019.

The data collected in this study was assessed, analysed and compared with previous series and the results are evaluated. In the present study the average age of occurrence of intertrochanteric fracture femur is 73.2 years with the range of presentation being 70 to 85 years. The average age incidences reported by other series were Launsten et al 77.1; Gilberty 72.5; Lestrange 79.7 In our study the no female patients are $18(60 \%)$ and the number of male patients 12 (40\%). The sex incidence reported in previous series were Launsten et al 77.3/22.7; Gilberty 81/19; Lestrange 81.8/ 18.2. The prosthesis size ${ }^{19}$ used varied from $39 \mathrm{~mm}$ to 51 mm. with nearly $76.67 \%$ requiring size $41 \mathrm{~mm}$ to $47 \mathrm{~mm}$. Prosthesis size used in males ranging from $43 \mathrm{~mm}$ to $51 \mathrm{~mm}$, females ranging from $39 \mathrm{~mm}$ to $45 \mathrm{~mm}$. The study of Langen (1979) had reported that majority of the patients (82\%) in their study, required prosthesis sizes between $44 \mathrm{~mm}-48$ $\mathrm{mm}$. The difference in the sizes in these study groups compared, may be partly due to racial differences in the build of patients. In the present study, $93 \%$ of patients had none to slight pain. Only 2 patients had mild pain in our study. This can be compared to other studies-- Launsten et al 75.6; Gilberty 82.5; Lestrange 69.7. This confirms that, bipolar prosthesis provides pain free hip in most of the patients. In the present study, $66.67 \%$ of the patients could walk for long distances with single cane support. This can be compared with other authors Wetherall \& Hinves $69 \%$ Gallannaugh $66 \%$. In the present study, there were no fixed deformities ${ }^{20}$. Two patients $(6.67 \%)$ had shortening of $1.5 \mathrm{~cm}$ and one patient $(3.33 \%)$ had lengthening of $1 \mathrm{~cm}$. This study when compared to other authors: Gallinaro (1990) has reported < $1 \mathrm{~cm}$ leg length discrepancy in $6.6 \%$ of his patients. Labelle (1990) has reported one patient with hip flexion contracture of $>5^{\circ}$. In the present study, most of our patients did not have restriction of daily activities. All patients could climb stairs with or without the help of railing, could sit comfortably on chair for long hours and all of them had no problem in putting on shoes \& socks. In our study, the final Harris Hip Score ranged from 56 to 93 with an average of 82 . Final Harris Hip Score of our study has been compared to other studies.

\section{CONCLUSIONS}

This study concludes that, though osteosynthesis by using dynamic hip screw or proximal femoral nail is most commonly preferred choice of treatment in stable inter trochanteric fractures, primary hemi replacement bipolar arthroplasty offers early painless mobility, ease of rehabilitation and early return to function, in complex unstable trochanteric fractures in the elderly and osteoporotic group. Our results are comparable to previous studies described in literature.

\section{REFERENCES}

[1] Kyle RF, Gustilo RB, Premer RF. Analysis of six hundred and twenty two intertrochanteric hip fractures. J Bone Joint Surg Am 1979;61(2):216-21.

[2] Zuckerman JD. Hip fractures. $N$ Engl J Med 1996;334(23):1519-25.

[3] Haentjens P, Casteleyn PP, De Boeck H, et al. Treatment of unstable intertro-chanteric and subtrochanteric fractures in elderly patients. Primary bipolar arthroplasty compared with internal fixation. J Bone Joint Surg 1989;71(8):1214-25.

[4] Harwin SF, Stern RE, Kulick RG. Primary Bateman leinbach bipolar prosthetic replacement of the hip in the treatment of unstable intertrochanteric fractures in the elderly. Orthopedics 1990;13(10):1131-6.

[5] Norton PL. Intertrochanteric fractures. Clin Orthop Relat Res 1969;66:77-81.

[6] Koval KJ, Sala DA, Knmmer FJ, et al. Postoperative weight-bearing after a fracture of the Femoral neck or an intertrochanteric fracture. J Bone Joint Surg Am 1998;80(3):352-6.

[7] Vonlangenba, Konig, Heygroves, et al. Nailing for IT fracture. Chap - 23. In: Ramon GB, Richard KF, David E, eds. Factures and dislocations. Vol. 2. Mosby 1993: p. 783-854.

[8] Jewett EL. One-piece angle nail for trochanteric fractures. Journal of Bone and Joint Surgery 1941;23(4):803-10.

[9] Lownail B, Watson-Jones. Fractures and joint injuries. $6^{\text {th }}$ edn. Vol. 2. B.I.: Churchill Livingstone 1992;29:878-973.

[10] Murray RC, Frew JFM. Trochanteric fractures of the femur. Journal of Bone and Joint Surgery 1949;31:20419. 
[11] Evans EM. The treatment of trochanteric fractures of the femur. Journal of Bone and Joint Surgery 1949;31B(2):190-203.

[12] Srivastva KP. Earnestroll-sliding device. In: Kulakarni GS, edr. Textbook of Orthopaedics and Trauma. Jaypee Brothers Medical Publishers (P) Ltd., Vol. 3. 1999: p. 2052-72.

[13] Thornton L, De Lee JC. Rockwood and Green's Fractures in adults. Chapter -18 . Vol. 2. $3^{\text {rd }}$ edn. Lippincott Company 1991: p. 1481-651.

[14] Pugh WL. A self-adjusting nail-plate for fractures about the hip joint. Journal of Bone and Joint Surgery Am 1955;37-A(5):1085-93.

[15] Massie WK. Functional fixation of femoral neck fractures. telescoping nail technique. Clinical Orthopaedics and Related Research 1958;12:230-55.
[16] Dimon JH, Hughston JC. Unstable Intertrochanteric fractures of the hip. Journal of Bone and Joint Surgery Am 1967;49(3):440-50.

[17] Kuntscher G. A new method of treatment of pertrochanteric fractures. Proceedings of the Royal Society of Medicine 1970;63(11 Part 1):1120-1.

[18] Heinman ML. Leinbach prosthesis in unstable intertrochanteric fractures. Contemp Orthop 1982;5:37.

[19] Giliberty RP. Bipolar endoprothesis minimizes protrusion acetabuli, loose stems. Ortho Review 1985;14:27.

[20] Haidukewych GJ, Berry DJ. Hip arthroplasty for salvage of failed treatment of intertrochanteric hip fractures. J Bone Joint Surg Am 2003;85(5):899-904. 